\title{
Influência católica no planejamento familiar: estudo sobre parentalidade responsável
}

\section{Catholic influence on family planning: a study in the context of catholic communities}

\author{
Mário Antônio Sanches* \\ Castorina Honorato Vidal Casagrande** \\ Marcio Luiz Fernandes*** \\ Daiane Priscila Simão-Silva****
}

\begin{abstract}
Resumo: Neste artigo, aborda-se a relação entre a Igreja Católica e planejamento familiar, com o objetivo de identificar o impacto da primeira sobre o segundo. A pesquisa é descritiva e analítica, a partir de revisão bibliográfica sobre os temas relacionados com planejamento familiar e também da pesquisa de campo com a aplicação do instrumento de pesquisa Planejamento da Parentalidade no Contexto da Bioetica. No total, foram avaliados 863 questionários relacionados à gravidez do primeiro filho e 614 relacionados à gravidez do último filho. Dentre os resultados da pesquisa, aponta-se que mais da metade dos entrevistados $(63,4 \%)$ atribuiu nota zero ou 1 à questáo apresentada: A religião influenciou na escolha do método contraceptivo?. No entanto, a percentagem dos que atribuiram nota máxima para o planejamento da gravidez do primeiro filho é de $42,3 \%$. Conclusôes: este artigo revela um saldo positivo em relação ao papel da religião na busca de uma parentalidade responsável porque identifica que a posição oficial de lideranças religiosas não esgota o rol de possibilidades de reflexão na própria religião sobre planejamento familiar. A pesquisa demostra que a posição da Igreja na escolha de métodos contraceptivos é acompanhada, também, de uma postura em prol de uma parentalidade responsável e de planejamento consensuado. A consideraçấo final que este artigo nos permite fazer é de que a religião é um fator importante em um programa que busque promover o planejamento familiar.
\end{abstract}

Palavras-chave: Religião. Planejamento Familiar. Parentalidade responsável.

Abstract: This article deals with the relationship between Catholic Church and family planning, with the goal of identifying the impact of the first on the second. The research is descriptive and analytical from literature review on issues related to family planning and a field research with the implementation of the instrument for Planning of parentality in the context of bioethics. In total were evaluated 863 questionnaires related to the pregnancy of the first child and 614 relate to the pregnancy of the last child. One of the results of the research points out that more than half of the respondents (63.4\%) assigned note zero or 1 to the question presented: Did religion influenced in the choice of contraceptive method? However, the percentage of assigned full marks for planning of pregnancy of the first child is $42.3 \%$. Conclusions: this article reveals a positive balance in relation to the role of religion in the search of a parental responsibility, because it identifies that the official position of religious leadership does not exhaust the list of possibilities for reflection on religion itself on family planning. The research demonstrates that the Church's position on choice of contraception is accompanied also by a posture for a parental responsibility and agreed planning. The final consideration that this article allows us to do is that religion is a major factor in a program that seeks to promote family planning.

Keywords: Religion. Family planning. Parental responsability.

* Doutor em Teologia (EST), professor no PPG em Teologia da PUC-PR. Contato: m.sanches@pucpr.br

** Doutoranda em Teologia (PUC-PR).

*** Doutor em Psicologia (USP), professor adjunto do PPG em Teologia da PUC-PR.

**** Doutora em Genética (UFPR), professora adjunta do PPG em Bioética da PUC-PR. 


\section{Introduçáo}

O presente artigo é parte de uma pesquisa mais ampla sobre planejamento familiar realizada por um grupo de pesquisa que vem aplicando o instrumento Planejamento da Parentalidade no Contexto da Bioética, que possibilita identificar as causas da ausência ou presença de projetos de parentalidade em pessoas que já tiveram filhos (Sanches, et al, 2015).

No estudo da reproduçáo humana, um dos maiores conflitos surge quando nos deparamos com a situação de pessoas com filhos ou mulheres grávidas que não delineiam um projeto de parentalidade explícito ou implícito. Há pesquisas apontando para um alto número de abortos:

Em cada ano, no mundo todo, aproximadamente 210 milhóes de mulheres engravidam e mais de 135 milhões dão à luz bebês vivos. As outras 75 milhóes de gravidezes terminam em interrupçáo do parto, por aborto espontâneo ou induzido. Estima-se que em 2003 aproximadamente 42 milhóes de gravidezes foram terminadas voluntariamente: 22 milhôes com segurança e 20 sem segurança (WHO, 2011, p. 2).

Esse é, portanto, o resultado mais dramático de uma gravidez sem projeto, mas certamente o aborto não é a sua única consequência, pois a gravidez é o centro de situaçóes com fortes implicaçóes para as mães, para as crianças, para as famílias e para os serviços de saúde.

Abordagens realizadas no âmbito religioso (SCDF, 1974) focam prioritariamente a defesa da vida e da dignidade da criança, enquanto no âmbito da saúde (Cavalcante; Xavier, 2008) o foco é a defesa da vida e da dignidade da mulher. Um estudo na área da bioética nos desafia a uma visão mais ampla, em que se pode desvendar a realidade a partir de perspectivas que nos permitam contemplar os dois focos da questáo: a dignidade da mãe e da criança.

No âmbito da reproduçáa humana, o projeto de ser pais - projeto de parentalidade - é situado no contexto global da vida total das pessoas envolvidas e da vida do casal. Mas, independentemente de seu conteúdo, constata-se um grande avanço para a sociedade quando as pessoas passam a explicitar a parentalidade como projeto, isto porque a transmissão da vida requer uma decisão pessoal e responsável (Haering, 1971, p. 41) e também porque "cada menino ou menina tem o indiscutível direito de ser desejado antes de ser concebido" (Beñeraf, 2006, p. 58).

O tema do planejamento familiar náo é novo e já estava presente na oitava conferência da Fundação da Federação Internacional de Planejamento Familiar em 1967, em Santiago do Chile, quando a presidente da Federação afirmava: "lutamos para que todos os filhos que venham ao mundo sejam bem-vindos" (Eguren, 1976, p. 54). Para que cada criança que nasça seja bem-vinda, é relevante que cada gravidez seja planejada, pois, quando isto não ocorre, instaura-se uma situaçáo de tensão que nem sempre tem resultado favorável ao acolhimento da criança. Por isso, o amadurecimento sem pressa dos projetos de parentalidade contribui para que este se efetive nas melhores 
condiçóes possíveis, como parte integrada no projeto de vida das pessoas envolvidas, pois: "um dos principais desafios das famílias no século XXI é enfrentar a carência de um modelo confiável e funcional de ser pais no mundo em mudança" (Solís-Pontón, 2006, p. xxxvii).

O contexto da pesquisa, portanto, não dá ênfase às questôes relativas aos métodos contraceptivos, mas ao planejamento da parentalidade, ou seja, busca identificar se as crianças nascem planejadas ou não, com a convicção de que filhos planejados podem ser mais facilmente acolhidos do que os não planejados. Também estamos cientes de que há muitos outros fatores que influenciam no pleno acolhimento de cada criança.

Assim, este artigo se insere no contexto da importância do planejamento familiar e na busca de identificar qual a influência das religióes neste planejamento. Tendo em vista a complexidade do tema - diversidade de contextos e a diversidade religiosa da nossa sociedade - é importante destacar o recorte do campo da pesquisa que fora realizada em comunidades católicas; a discussão, portanto, se dará a partir deste recorte, com os dados de pesquisa de campo e as orientações da Igreja Católica sobre o assunto, pensando sempre na influência da religião no planejamento familiar.

\section{Metodologia}

Este artigo é fruto de pesquisa descritiva e analítica, de modo que a metodologia utilizada comportou uma revisão bibliográfica sobre o tema e pesquisa de campo. A pesquisa de campo foi efetivada a partir da aplicação do instrumento de pesquisa citado anteriormente, que consta de 56 questóes relacionadas ao planejamento familiar. Os questionários foram aplicados nas seguintes cidades do Estado do Paraná: Londrina, Apucarana, Jacarezinho, Campo Mourão, São José dos Pinhais e Curitiba, em encontros, palestras, reunióes e cursos de formação dos agentes de pastorais da Igreja. No total, foram respondidos 863 questionários relacionados à gravidez do primeiro filho e 614 relacionados à gravidez do último filho.

Este artigo foi elaborado a partir da hipótese de que a religião desempenha forte influência no planejamento familiar e, por causa disto, as pessoas mais atuantes em determinada religiáo realizam o planejamento familiar a partir das suas respectivas orientaçóes doutrinárias. Desse modo, foram analisadas neste artigo as respostas à pergunta do questionário: "A religiáo influenciou na escolha do método contraceptivo?". Essa pergunta foi cruzada com duas outras questóes relacionadas à gravidez do primeiro filho: "Você planejou a gravidez do seu primeiro filho?" e "A gravidez do seu primeiro filho foi um projeto do casal - uma decisão tomada a dois?" As questôes apresentadas aos participantes da pesquisa tinham múltiplas escolhas; neste caso, o entrevistado deveria dar uma nota de zero a quatro para cada questáo, sendo que quanto mais alta fosse a atribuição, maior a influência da religião na sua decisão.

Os perfis de gênero e etário dos entrevistados no contexto desta pesquisa (Tabela 1) revela uma maioria feminina e acima de 36 anos. Esse perfil precisa ser considerado na análise dos dados. 
Tabela 1 - Perfil geral dos entrevistados por gênero e idade atual. GÊNERO PERCENTAGEM (\%) No DE ENTREVISTADOS

\begin{tabular}{ccc}
\hline Masculino & 27,7 & 239 \\
\hline Feminino & 71,5 & 617 \\
\hline não respondeu & 0,8 & 7 \\
\hline IDADE & PERCENTAGEM (\%) & $\mathbf{N}^{\circ}$ DE ENTREVISTADOS \\
\hline Entre 18 e 25 anos & 1,6 & 14 \\
\hline Entre 26 e 35 anos & 11,7 & 101 \\
\hline Entre 36 e 45 anos & 34,4 & 297 \\
\hline Entre 46 e 60 anos & 36,7 & 317 \\
\hline Acima de 60 anos & 11.8 & 102 \\
\hline não respondeu & 3,7 & 32 \\
\hline Total & $\mathbf{1 0 0 , 0}$ & $\mathbf{8 6 3}$
\end{tabular}

Fonte: elaboração dos autores (2016).

\section{Influência da Igreja no planejamento familiar}

No Cristianismo como um todo e, mais especificamente, na Igreja Católica, defendeu-se que a relação sexual deve ser realizada no âmbito do matrimônio e, assim, reproduziu-se aquilo que já estava presente nas sociedades ocidentais: a defesa da monogamia como princípio para matrimônio. Com a regulação do comportamento sexual, seja por meio da educação ou da interdiçáo, tanto a Igreja quanto a sociedade exercem um controle sobre a vida sexual dos seus membros e, como consequência, influenciam no número de filhos. A regulação do comportamento sexual não é uma realidade exclusiva da sociedade ocidental: ela pode ser vista em várias culturas e contribui para sua unidade e coesão interna, de modo que Vidal (2002, p. 236) destaca que o "casamento deve sua estabilidade social às tarefas em benefício da segurança e do sustento que os pais realizam com relação aos filhos e aos cônjuges entre si”.

Esse contexto, que situa a sexualidade no âmbito do matrimônio e voltado para a geração da prole, marca o pensamento da Igreja ao longo de sua história. No século XX, essa posição é retomada e desenvolvida, iniciando por Pio XI na Carta Encíclica Casti Connubbii, que ensina que a "prole ocupa o primeiro lugar dentre os bens do matrimônio" (N.6). Deste modo, os filhos, antes apontados com um dos fins do matrimônio, é aprestando aqui com um dos seus preciosos bens.

O pensamento da Igreja, na sequência, admite a possibilidade de se falar em planejamento familiar, no sentido de limitar o número de filhos. Isso ocorre a partir das descobertas científicas no século XX, quando, em 1924, Kyusaku Ogino publicou no Japão um trabalho apresentando novos dados sobre o período estéril feminino e em 
1929, sem o conhecimento da pesquisa de Ogino, Hermann Knaus, um médico austríaco, publicou o resultado de sua pesquisa chegando à mesma conclusáo (Noonan, 1965, p. 443). A partir dessas descobertas, divulgou-se o que ficou conhecido como o método Ogino-Knaus, que foi aceito pela Igreja, quando em 1951 Pio XII falou à Sociedade Católica Italiana de Parteiras, um grupo de enfermeiras especializadas em casos de maternidade, afirmando que o intercurso sexual nos dias férteis pode ser lícito. Os motivos para evitar a procriação, por meio dos ritmos, podem ser médicos, econômicos e sociais (Noonan, 1965, p. 446).

A pílula anticoncepcional, lançada nos Estados Unidos na década de 1960 pelo americano Gregory Goodwin Pincus com a colaboração de Margaret Sanger e a feminista Katherine Mc Cormick, representou uma revoluçáo para a sexualidade, pois com ela as pessoas poderiam evitar a gravidez, e o intercurso sexual poderia estar voltado exclusivamente para o prazer. No entanto, os efeitos colaterais do uso da pílula no organismo das mulheres foram aparecendo, como o ganho de peso, náuseas e enxaquecas, entre outros, devido ao fato de que a primeira versão da pílula, a Enovid-10, continha os hormônios estrógenos e progesterona sintética em doses muitos altas. (Aldrighi, 2018). Sabe-se que a indústria farmacêutica continuou evoluindo e desenvolveu uma enorme variedade de anticoncepcionais e contraceptivos. Todos possuem grande eficácia se usados de acordo com as prescriçóes médicas, mas não deixaram de ter efeitos colaterais na saúde das mulheres.

É nesse contexto que a Igreja Católica retoma a questão, incluindo seu posicionamento em relação aos métodos artificiais, tais como a pílula anticoncepcional. Em 1962, o então Papa João XXIII abria o Concílio Vaticano II e, ainda em seu pontificado, instituiu a Comissáo Papal para o Estudo da População, da Família e da Natalidade, demostrando que a Igreja estava preocupada com a discussáo sobre o controle da natalidade. Enquanto se aguardava a conclusão do relatório da comissão, em 1965, no pontificado de Paulo VI, como resultado do Concílio Vaticano II, houve a promulgação da Constituição Sobre a Igreja no Mundo de Hoje - Gaudium et Spes (GS). Nessa constituição, com respeito ao controle da natalidade, o Concílio não determinou nenhuma posiçáo concreta como sendo do magistério, e afirma que o amor conjugal se destina à geraçáo e educaçáo dos filhos, e que os esposos são colaboradores com o amor do Criador e Salvador (GS, n. 50).

O relatório da maioria da comissáo criada pelo Papa recomenda uma abertura aos métodos contraceptivos quando reconhece que "a intervenção humana no processo do ato matrimonial por razóes tiradas da finalidade do próprio matrimônio não deveria ser sempre excluída” (Kosnik, et al, 1982: p. 67 apud Ford e Kelly, 1963, p. 256ss). Porém, contrariando as expectativas de grande parte da Igreja Católica, que esperava um sim aos métodos artificiais de controle da natalidade, Paulo VI rejeita as conclusóes da comissão e, em 1968, promulga a encíclica Humanae Vitae.

Esta encíclica, de acordo com Kosnik et al. (1982, p. 68), "reafirma a posição de Pio XI e Pio XII (...) e representa a posiçáo oficial do supremo Magistério da Igreja”. Respeitar a natureza e a finalidade do ato matrimonial - na perspectiva da Encíclica - era dizer que "a relação sexual deveria permanecer aberta à transmissão da vida” (HV, n. 11) e, portanto, significava rejeitar os métodos artificiais, tais como métodos químicos ou de barreira. 
Desse modo, desde o final da década de 1960, com o surgimento e desenvolvimento das pílulas anticoncepcionais e a promulgação da encíclica Humanae vitae pelo Papa Paulo VI, ampliou-se as divergências entre o "ensino oficial da Igreja e a concreta praxe dos fiéis" (Kosnik, et al., 1982, p. 69). Sabe-se que a encíclica provocou muitas reações dentro da própria Igreja. Ninguém entendia o fato de o Papa Paulo VI ter se colocado ao lado de uma minoria, que defendia o método natural, como único meio lícito de prevenir a gravidez. Charbonneau (1969, p. 15ss) relata que "desde os mais celebres teólogos até os mais simples fieis, praticamente ninguém poderia contar com tal retrocesso. Era assombroso, após o Concílio Vaticano II, ter que ouvir novamente uma linguagem com a qual não se estava mais familiarizado desde 1951".

Na sociedade como um todo, a partir da década de 1960, ocorreu uma espécie de liberalismo, em que levantar dúvidas sobre o planejamento familiar era estar em descompasso com a história. Nas sociedades ocidentais, as pessoas passam a ter autonomia para decidir o número de filhos e qual método utilizar para evitar a gravidez, com a compreensão de que a Igreja Católica não teria mais nada a dizer sobre questóes que já haviam sido resolvidas pela ciência (Moser, 2014, p. 60). É importante salientar que, independente das reações contra a encíclica Humanae Vitae, o Vaticano II contribuiu para que a visão da sexualidade sofresse grande transformação dentro da Igreja Católica, pois se introduziu uma nova compreensão da dimensão pessoal da sexualidade humana e de sua importância para o desenvolvimento integral do indivíduo, que será analisado abaixo.

Essa rápida revisão do posicionamento mais recente da Igreja sobre a contracepção é relevante para situarmos os dados da pesquisa de campo apresentados na Tabela 2. Nessa tabela, evidencia-se que a atenção dos fiéis católicos à palavra normativa transmitida por meio de documentos do magistério exerce pouca influência na vida e vivência dos casais cristáos quando o assunto é explicitamente a escolha de métodos contraceptivos. Dos 863 entrevistados, 63,4\% deram nota zero ou 1 à questáo apresentada: $A$ religião influenciou na escolha do método contraceptivo?, enquanto $22.2 \%$, atribuíram notas 3 e 4 .

\section{Tabela 2 - A religiáo influenciou na escolha do método contraceptivo?}

\begin{tabular}{ccc} 
& Frequência & Porcentagem (\%) \\
\hline 0 & 489 & 56,7 \\
\hline 1 & 58 & 6,7 \\
\hline 2 & 94 & 10,9 \\
\hline 3 & 44 & 5,1 \\
\hline 4 & 148 & 17,1 \\
\hline náo respondeu & 30 & 3,5 \\
\hline Total & 863 & 100,0
\end{tabular}

Fonte: elaboração dos autores (2016). 
Essa fraca influência da Igreja na escolha de métodos contraceptivos não reflete o quadro completo da problemática do planejamento familiar no âmbito eclesial, como será discutido a seguir.

\section{Parentalidade responsável}

Pode-se dizer que o fato de a Igreja assumir explicitamente a posiçáo contrária ao uso dos métodos contraceptivos artificias fez com que ela deixasse de influenciar na escolha de métodos contraceptivos como um todo. No entanto, permaneceu na Igreja Católica uma reflexão teológica mais ampla, influenciada pelo Vaticano II, que destaca a importância da parentalidade responsável. Por isso, Sanches e Simão-Silva (2016, p. 79) defendem a necessidade de fazer distinçōes neste amplo campo que é usualmente chamado de 'planejamento familiar'. Para os propósitos deste artigo, é relevante destacar a diferença entre "planejar a gravidez", que evidentemente implica definir métodos contraceptivos, e "planejar a parentalidade", que requer pensar o acolhimento responsável dos filhos. Essa diferença nos possibilita compreender que as pessoas podem lançar mão de diferentes métodos para planejar ou não a gravidez, mas, mesmo assim, podem estar assumindo uma parentalidade responsável. Ou seja, não é apenas a escolha ou rejeição de um determinado método contraceptivo que define a responsabilidade parental.

Talvez isto explique os dados apresentados na Tabela 3, na qual a percentagem dos que atribuíram nota máxima para o planejamento da gravidez do primeiro filho é de $42,3 \%$, bem maior do que os $17,1 \%$ que afirmaram terem sido influenciados pela Igreja. Ou seja, para o grupo de agentes de pastoral pesquisado, o planejamento familiar está presente em uma percentagem bem superior ao reconhecimento da influência da Igreja sobre a escolha de métodos contraceptivos.

\section{Tabela 3 - Planejamento da gravidez do primeiro filho.}

\begin{tabular}{ccc} 
& Frequência & Porcentagem \\
\hline 0 & 322 & 37,3 \\
\hline 1 & 52 & 6,0 \\
\hline 2 & 52 & 6,0 \\
\hline 3 & 63 & 7,3 \\
\hline 4 & 365 & 42,3 \\
\hline náo respondeu & 9 & 1,0 \\
\hline Total & 863 & 100,0
\end{tabular}

Fonte: elaboração dos autores (2016).

O fato de praticamente a metade $(49,6 \%)$ dos agentes de pastoral pesquisados planejar a gravidez do primeiro filho (notas 3 e 4), pode estar apontando para uma 
preocupação mais ampla de toda a sociedade com a responsabilidade parental, preocupação esta também presente na Igreja Católica. Pode-se dizer que o contexto atual é de amplo acesso a anticoncepcionais, mas isto não está necessariamente desvinculado de preocupaçóes com a parentalidade responsável. Há, por parte da sociedade como um todo, de governo, igrejas, escolas e imprensa, entre outros, um crescente incentivo ao planejamento familiar, visto como uma necessidade para que os filhos sejam pensados e criados responsavelmente, ou seja, em vista a uma parentalidade responsável. No Brasil, o planejamento familiar é transformado num direito do cidadão, para o qual a pessoa pode solicitar apoio do Estado, conforme a Constituição Federal, Artigo 226, $\$ 7^{\circ}$ :

Fundado nos princípios da dignidade da pessoa humana e da paternidade responsável, o planejamento familiar é livre decisáo do casal, competindo ao Estado propiciar recursos educacionais e científicos para o exercício desse direito, vedada qualquer forma coercitiva por parte de instituiçôes oficiais ou privadas.

Na reflexão teológica isto também está presente, pois, após a Humanae Vitae, um importante desenvolvimento da teologia da moral elaborou uma visão mais evangélica da sexualidade do matrimônio e do pecado, ampliando assim, o diálogo com o mundo sob a inspiraçáo do Vaticano II. O amor profundo, a abertura à vida, são exigências evangélicas que passaram a pautar as reflexóes sobre planejamento familiar e a questão moral se volta para as atitudes, e não mais para os métodos. A ênfase na responsabilidade visa a superaçáo do egoísmo e aponta para a importância da fecundidade em sentido mais amplo, não apenas no âmbito da reprodução (Moser, 2014, p. 62).

Talvez esse desenvolvimento da teologia, com base no Vaticano II, permitiu que uma grande percentagem de fiéis cristãos, e mesmo agentes de pastoral - como na pesquisa realizada - deixasse de lado as orientaçóes explícitas da Humanae Vitae contrária ao uso de métodos contraceptivos artificiais, mas se voltasse para o exercício de uma parentalidade responsável num sentido mais amplo, compreendendo que a problemática não se reduz à questão de qual método utilizar.

De acordo com a encíclica de João Paulo II Evangelium Vitae, o ser humano por meio da geração, "de certa forma participa nos domínios de Deus. Esta participação se manifesta na específica responsabilidade que lhe está confiada no referente à vida propriamente humana" (EV, n.43). Percebe-se, assim, que as palavras responsabilidade e amor estáo vinculadas a paternidade e maternidade. Nesse contexto, o projeto de parentalidade defendido pela literatura cientifica náo está muito distante da visão de planejamento familiar da Igreja Católica, pois "o motivo de ter filhos passa a ser o amor recíproco dos esposos que os faz desejar os filhos para fazê-los partícipes de seu pacto, de sua comunidade de amor" (Haerig, 1971, p. 44).

Desse modo, os dados e a reflexão nos levam à percepçáo de dois aspectos interessantes: a) muitos católicos valorizam o planejamento da parentalidade, no sentido da responsabilidade parental, mesmo não acatando a posição da Igreja sobre os métodos contraceptivos artificias; b) o expressivo número de católicos - 22,2\% na 
amostra da pesquisa realizada - que afirmam ter sido influenciados pela Igreja na escolha do método contraceptivo, manifestaram também uma melhor consciência de responsabilidade parental.

Este segundo aspecto se observa na Tabela 4, pois dos 148 (22,2\%) respondentes que atribuíram nota 4 para a influência da religiáo na escolha do método contraceptivo, $54,7 \%$ deram nota 4 no planejamento da gravidez do primeiro filho. Por outro lado, dentre os 489 respondentes que deram nota 0 para a influência da religião no mesmo tema, apenas $36,6 \%$ atribuíram nota 4 para o planejamento da gravidez do primeiro filho. Os cálculos estatísticos indicam que há correlação entre a influência da Igreja na escolha do método contraceptivo, com o planejamento da gravidez do primeiro filho $(\mathrm{P}=0,179 ; \mathrm{p}=0,00)$. Do mesmo modo, confirmando a hipótese apresentada, a religião influenciou no nível de planejamento do primeiro filho $\left(x^{2}=14,38 ; p=0,00\right)$.

Tabela 4 - Relação entre a influência da religiáo na escolha do método contraceptivo e o planejamento da gravidez do primeiro filho.

\begin{tabular}{|c|c|c|c|c|c|c|c|c|}
\hline \multirow{2}{*}{\multicolumn{2}{|c|}{$\begin{array}{l}\text { A influência da } \\
\text { religiáo na escolha } \\
\text { do método }\end{array}$}} & \multicolumn{7}{|c|}{ Planejamento da gravidez do seu primeiro filho } \\
\hline & & \multirow{2}{*}{$\begin{array}{c}\mathbf{0} \\
212\end{array}$} & \multirow{2}{*}{$\begin{array}{c}\mathbf{1} \\
32 \\
\end{array}$} & \multirow{2}{*}{2} & \multirow{2}{*}{$\begin{array}{c}3 \\
33 \\
\end{array}$} & \multirow{2}{*}{$\begin{array}{c}4 \\
179 \\
\end{array}$} & \multirow{2}{*}{$\begin{array}{c}\begin{array}{c}\text { náo } \\
\text { respondeu }\end{array} \\
4\end{array}$} & \multirow{2}{*}{$\frac{\text { Total }}{489}$} \\
\hline O & No & & & & & & & \\
\hline 0 & $\%$ & 43,4 & 6,5 & 5,9 & 6,7 & 36,6 & 0,8 & 100,0 \\
\hline \multirow{2}{*}{1} & No & 25 & 6 & 1 & 1 & 25 & 0 & 58 \\
\hline & $\%$ & 43,1 & 10,3 & 1,7 & 1,7 & 43,1 & 0,0 & 100,0 \\
\hline \multirow{2}{*}{2} & $\mathrm{No}$ & 23 & 4 & 14 & 11 & 41 & 1 & 94 \\
\hline & $\%$ & 24,5 & 4,3 & 14,9 & 11,7 & 43,6 & 1,1 & 100,0 \\
\hline \multirow{2}{*}{3} & No & 9 & 1 & 6 & 3 & 25 & 0 & 44 \\
\hline & $\%$ & 20,5 & 2,3 & 13,6 & 6,8 & 56,8 & 0,0 & 100,0 \\
\hline \multirow{2}{*}{4} & No & 43 & 8 & 2 & 14 & 81 & 0 & 148 \\
\hline & $\%$ & 29,1 & 5,4 & 1,4 & 9,5 & 54,7 & 0,0 & 100,0 \\
\hline \multirow{2}{*}{$\begin{array}{l}\text { não } \\
\text { respondeu }\end{array}$} & No & 10 & 1 & 0 & 1 & 14 & 4 & 30 \\
\hline & $\%$ & 33,3 & 3,3 & 0,0 & 3,3 & 46,7 & 13,3 & 100,0 \\
\hline \multirow{2}{*}{ Total } & No & 322 & 52 & 52 & 63 & 365 & 9 & 863 \\
\hline & $\%$ & 37,3 & 6,0 & 6,0 & 7,3 & 42,3 & 1,0 & 100,0 \\
\hline
\end{tabular}

Fonte: elaboração dos autores (2017).

Os dados acima, sobre planejamento familiar, podem ser confirmados pela pesquisa "Desafios do Catolicismo na Cidade" (CERIS, 2002: p. 201), em que os pesquisadores afirmam que $77,5 \%$ dos católicos são favoráveis ao planejamento da família. $\mathrm{O}$ uso de métodos contraceptivos é aceito por $73,2 \%$ dos católicos. Ambas as pesquisas revelam que, entre os católicos entrevistados, há o consenso de opinióes favoráveis ao planejamento familiar - no sentido de parentalidade responsável - mesmo não acolhendo a posição da Igreja sobre métodos contraceptivos artificiais. 


\section{Planejamento parental consensuado}

Outra agenda do planejamento familiar que encontra amplo apoio da sociedade organizada é o reconhecimento da igualdade de gêneros e a luta pela superação da violência a ela relacionada. Essa agenda é relevante para o planejamento familiar e conta com o apoio da Igreja, pois implica repudiar claramente a imposição do ato sexual e a prática de violência contra as mulheres e afirma que a decisão de ter filhos deve ser consensuada entre as pessoas envolvidas e não a decisão de um parceiro apenas (Sanches, 2013, p. 42).

Nesse aspecto extremamente relevante e sensível da realidade atual, a pesquisa revela que a influência da Igreja também foi significativa. A Tabela 5 aponta que 54,8\% dos pesquisados atribuem nota 4 à pergunta: $A$ gravidez do seu primeiro filho foi um projeto de casal?

\section{Tabela 5 - A gravidez do primeiro filho como um projeto de casal?}

\begin{tabular}{ccc} 
& Frequência & Porcentagem (\%) \\
\hline 0 & 268 & 31,1 \\
\hline 1 & 32 & 3,7 \\
\hline 2 & 47 & 5,4 \\
\hline 3 & 29 & 3,4 \\
\hline 4 & 473 & 54,8 \\
\hline náo respondeu & 14 & 1,5 \\
\hline Total & 863 & 100,0
\end{tabular}

Fonte: elaboração dos autores (2016).

No entanto, quando os dados foram cruzados com a questáo da influência da religião na escolha do método contraceptivo na gravidez do primeiro filho, percebe-se uma diferença significativa nos grupos de pesquisados, como mostra a Tabela 6. Entre os respondentes que deram nota 4 para a influência da religião na escolha do método contraceptivo, a percentagem daqueles que dizem que o primeiro filho foi um projeto do casal é de 68,9\%. Nesse caso, a Igreja Católica, quando influencia o planejamento de uma parentalidade responsável, também impacta a decisão de a gravidez ser um projeto do casal e não uma decisão unilateral. Os cálculos estatísticos indicam correlação positiva entre a influência da religiáo na escolha do método contraceptivo e a gravidez do primeiro filho ser projeto do casal $(\mathrm{P}=$ $0,171 ; \mathrm{p}=0,00)$. 
Tabela 4-Correlaçáo entre a influência da religião na escolha do método contraceptivo cruzada com a gravidez do primeiro filho como um projeto de casal.

\begin{tabular}{|c|c|c|c|c|c|c|c|c|}
\hline \multirow{2}{*}{\multicolumn{2}{|c|}{$\begin{array}{l}\text { A influência da } \\
\text { religiáo na escolha } \\
\text { do método }\end{array}$}} & \multicolumn{7}{|c|}{ A gravidez do primeiro filho foi um projeto de casal } \\
\hline & & \multirow{2}{*}{$\begin{array}{c}\mathbf{0} \\
189 \\
\end{array}$} & \multirow{2}{*}{1} & \multirow{2}{*}{$\frac{2}{22}$} & \multirow{2}{*}{$\frac{3}{15}$} & \multirow{2}{*}{$\begin{array}{c}4 \\
242 \\
\end{array}$} & \multirow{2}{*}{$\begin{array}{c}\begin{array}{c}\text { não } \\
\text { respondeu }\end{array} \\
5 \\
\end{array}$} & \multirow{2}{*}{$\begin{array}{c}\text { Total } \\
489 \\
\end{array}$} \\
\hline 0 & No & & & & & & & \\
\hline 0 & $\%$ & 38,7 & 3,1 & 4,5 & 3,1 & 49,6 & 1,0 & 100,0 \\
\hline \multirow{2}{*}{1} & No & 15 & 7 & 5 & 3 & 28 & 0 & 58 \\
\hline & $\%$ & 25,9 & 12,1 & 8,6 & 5,2 & 48,3 & 0,0 & 100,0 \\
\hline \multirow{2}{*}{2} & No & 18 & 5 & 9 & 6 & 55 & 1 & 94 \\
\hline & $\%$ & 19,1 & 5,3 & 9,6 & 6,4 & 58,5 & 1,1 & 100,0 \\
\hline \multirow{2}{*}{3} & No & 7 & 0 & 4 & 3 & 29 & 1 & 44 \\
\hline & $\%$ & 15,9 & 0,0 & 9,1 & 6,8 & 65,9 & 2,3 & 100,0 \\
\hline \multirow{2}{*}{4} & No & 33 & 4 & 7 & 2 & 102 & 0 & 148 \\
\hline & $\%$ & 22,3 & 2,7 & 4,7 & 1,4 & 68,9 & 0,0 & 100,0 \\
\hline \multirow{2}{*}{$\begin{array}{c}\text { não } \\
\text { respondeu }\end{array}$} & No & 6 & 1 & 0 & 0 & 17 & 6 & 30 \\
\hline & $\%$ & 20,0 & 3,3 & 0,0 & 0,0 & 56,7 & 20,0 & 100,0 \\
\hline \multirow{2}{*}{ Total } & No & 268 & 32 & 47 & 29 & 473 & 13 & 863 \\
\hline & $\%$ & 31,1 & 3,7 & 5,5 & 3,4 & 54,9 & 1,5 & 100,0 \\
\hline
\end{tabular}

Fonte: elaboração dos autores (2016).

\section{Consideraçóes finais}

Este artigo, ao abordar a problemática da influência da Igreja Católica no planejamento familiar e elaborado a partir de pesquisa realizada no âmbito de suas comunidades, revela que a questáo é complexa e precisa ser aprofundada, mas certamente traz um saldo muito positivo do papel desta religiáo na busca de uma parentalidade responsável. Talvez alguns aspectos aqui considerados extrapolam a realidade pesquisada e podem estar presentes também no âmbito de outras confessionalidades, o que precisa ser verificado.

A posição oficial do Magistério da Igreja Católica contrária à utilizaçáo de métodos contraceptivos artificiais, amplamente conhecida pela sociedade, não esgota o rol de possibilidades de reflexão na própria Igreja sobre planejamento da parentalidade. Por isso, a pesquisa capta um comprometimento de agentes de pastoral da Igreja com a parentalidade responsável em percentagem muito maior do que a percentagem dos que aceitam a influência da Igreja na escolha de métodos contraceptivos. Certamente isto também é reflexo de transformaçóes sociais ocorridas nas últimas décadas e das conquistas científicas dos últimos tempos, mas nos permite dizer que, no âmbito do planejamento familiar, a prática concreta das pessoas de uma determinada denominação religiosa não reflete as proposiçôes oficiais de sua liderança.

A pesquisa demostra que a posiçấo da Igreja na escolha de métodos contraceptivos é acompanhada também de uma postura em prol de uma parentalidade responsável, de 
modo que os agentes de pastoral que declaram aceitar a influência da Igreja no primeiro, indicam também maior preocupaçáo com o segundo aspecto desta complexa temática. Ou seja, a percentagem que afirma ter planejado a gravidez do primeiro filho é maior entre aqueles que aceitam a influência da Igreja na escolha dos métodos contraceptivos.

Igualmente relevante é o maior índice de planejamento consensuado entre os que afirmam ter sido influenciado pela Igreja do que entre os outros pesquisados. Certamente a parentalidade responsável não se esgota no fato de os parceiros planejarem seus filhos em comum acordo, mas indubitavelmente este é um ponto relevante e, neste panorama, cresce a possibilidade de os filhos serem acolhidos com responsabilidade. Certamente, o planejamento familiar consensuado, além de sua forte motivação religiosa, é um elemento de grande apelo ético para toda a sociedade.

A consideração final que este artigo nos permite fazer é que a religião é um fator importante em um programa que busque promover o planejamento familiar, principalmente quando o foco é dado no acolhimento da criança, ou seja, no planejamento para que os filhos e filhas sejam amadas e acolhidas mesmo antes de sua concepçáo. Isso porque as religióes, ao apontar para a necessária harmonia do casal e sua responsabilidade para com os filhos, estão apontando para conteúdos específicos e práticos do planejamento familiar. No entanto, mesmo que proposições religiosas oficiais apontem no sentido contrário, o chamado à responsabilidade parental implica na possibilidade de evitar a concepção de filhos não desejados, quando os pais sentem não poder acolhê-los adequadamente. Seria contraditório defender um planejamento familiar responsável sem permitir que os próprios envolvidos no planejamento decidam se/quando/quantos filhos querem ter.

\section{Referências}

ALDRIGHI, José Mendes. Pílulas anticoncepcionais. 2018. Disponível em: https:// drauziovarella.uol.com.br/entrevistas-2/pilulas-anticoncepcionais/. Acessado em 15/04/2018.

BENEERAF, L.F. Los Orígenes de la violência y la segunda revolución in psicoanálisis. In: SOLÍS-PONTÓN, L.; BECERRA, T.L.; MALDONADODURÁN, M. La cultura de la paternidade: antídoto contra la violência y la barbárie. México: Manual Moderno, 2006, pp. 46-48.

BRASIL. CONSTITUIÇÃO 1988. Constituição: República Federativa do Brasil. Brasília, DF: Senado Federal, 1988.

CAVALCANTE, A.; XAVIER, D. (Orgs.). Aborto: uma visão humanística. Estudos Feministas, Florianópolis, 16(2): 691-713, maio-agosto/2008.

CERIS, Centro de Estatística Religiosa e Investigaçôes Sociais. Desafios do catolicismo na cidade: pesquisa em regiōes metropolitanas brasileiras/CERIS. Ed. Paulus, São Paulo, SP, 2002. 
CONCÍLIO ECUMÊNICO VATICANO II. Constituição Pastoral Gaudium et Spes. Trad. Francisco Catáo. 2a ed. Ed. Paulinas, São Paulo, SP, 2007

CHARBONNEAU, Paul-Eugène. Humanae Vitae: E liberdade de consciência. Ed. Herder, São Paulo, SP, 1969.

EGUREN, J. A. Paternidad responsable y valores humanos: aportación al diálogo sobre la planificación familiar. Valencia: Edicep, 1976.

FORD, John; KELLY, Gerald. Contemporary Moral Theology. Westminster, Md. New-man Press, 1963. Apud KOSNIK, A.; et al. A sexualidade humana: novos rumos do pensamento católico Americano. Ed. Vozes, Petrópolis, São Paulo, 1982.

GRUPO PARENTALIDADE: Pesquisa aprovada pelo Comitê de Ética em pesquisa da PUCPR com o parecer: 770.977, 27/08/2014. Lei 9.263/96.

HAERING, B. Paternidad responsables. Bogotá: Paulinas, 1971.

KOSNIK, Antony; et al. A sexualidade humana: Novos rumos do pensamento católico Americano. Ed. Vozes, Petrópolis, São Paulo, 1982.

MOSER, Antônio. Planejamento familiar na Igreja Católica: do ruído estrondoso a um silêncio perturbador. In: SANCHES, MA (Org.). Bioética e planejamento familiar: perspectivas e escolhas. Ed. Vozes, Petrópolis, RJ. 2014.

NOONAN, Jr, John T. Contraception: A history of its treatment by the Catholic theologians and canonists. Cambridge, Massachusetts: Harvard University Press, 1965, p. 443-446.

PAPA PAULO VI. Carta Encíclica Humanae Vitae: sobre a regulaçáo da natalidade. $12^{a}$ ed. Ed. Paulinas. São Paulo, SP, 2010.

PAPA JOÃO PAULO II. Evangelium Vitae. Carta Encíclica sobre o valor e a inviolabilidade da vida humana. Ed. Paulinas, São Paulo, SP, 2007.

PAPA PIO XI. Casti Connubii. Carta encíclica Sobre el Matrimonio Cristiano.

Disponível em: http://w2.vatican.va/content/pius-xi/es/encyclicals/documents/hf pxi enc 19301231 casti-connubii.html. Acesso em 26/06/2018.

SAGRADA CONGREGAÇÃO PARA A DOUTRINA DA FÉ (SCDF). Declaração Sobre o Aborto Provocado, 19974. Disponível em: http://www.vatican. va/roman curia/congregations/cfaith/documents/rc con cfaith doc 19741118 declaration-abortion po.html, 1974.

SANCHES, Mário Antônio. Reprodução assistida e bioética: metaparentalidade. Ed. Ave-Maria. São Paulo, SP, 2013.

.et al. Planejamento da Parentalidade no contexto da bioética: busca de uma nova abordagem para pesquisa. Ed. Universitária Champagnat, PUCPR. Curitiba, PR, 2015. 
144 Mário Antônio Sanches et alli

SANCHES, M.A; SIMÃO-SILVA, D.P. Planejamento Familiar: do que estamos falando? Revista Bioética, v. 24, n. 1, 2016.

SOLÍS-PONTÓN, L.; BECERA, T.L.; MALDONADO-DURÁN, M. La cultura de la parentalidade: antidoto contra la violência y la barbárie. México: Manual Moderno, 2006.

VIDAL, Marciano. Ética da Sexualidade. Edições Loyola, São Paulo, SP, 2002.

WORLD HEALTH ORGANIZATION (WHO). Unsafe abortion: global and regional estimates of the incidence of unsafe abortion and associated mortality in 2008. Geneva, World Health Organization, 2011.

Recebido: 25 de maio de 2018.

Aprovado: 29 de junho de 2018. 